\title{
Value-semantic factors of teachers' professional growth in the context of the longevity problem
}

\author{
Natalia Zotova $^{1 *}$, and Mikhail Tikhomirov ${ }^{1}$ \\ ${ }^{1}$ Volgograd State Social and Pedagogical University, Department of Psychology of Professional \\ Activity, 400066, Volgograd, Russian Federation
}

\begin{abstract}
The article discusses the study results of the Russian teachers' professional longevity. The authors try to highlight the role of valuesemantic factors that determine the teacher's orientation to the productive extension of his professional path beyond the retirement age. The study results, in particular, the analysis of data from in-depth interviews with teachers of retirement age $(\mathrm{n}=40)$ allows us to assert a significant contribution of value-semantic factors to the overall picture of the process of a teacher's transition to the post-professional period of his life. In particular, three main transition strategies are identified: 1. Postponement; 2. Smooth transition; 3. Forced finish. Each strategy corresponds to a certain type of indicators of a value-semantic nature: attitude to health, attitude to the level of one's professional efficiency, combining professional and personal goals. There is a high diagnostic value of the metaphor method in the study of the respondents' professional path.
\end{abstract}

\section{Introduction}

In the modern world, much attention is paid to the problems of education, as it is such process that ensures the cultural and technological prosperity of any nation. At the same time, one can hardly object to the thesis about the decisive role of the teacher's personality in the educational process. Numerous researches confirm the position that interest in learning in general, interest in a specific area of knowledge, student self-esteem and the level of his educational achievements depend primarily on the teacher's competence. Thus, the most important goal of any educational system that cares about the quality of education is to create conditions for the professional and personal growth of teachers, and especially those who continue to work productively in adulthood. In addition, the issues of maintaining vigor, psychological and physical health, effective solution of complex professional problems throughout many years of life and the interested participation of mature teachers in support programs for young specialists are considered at the present stage from the standpoint of the demand for scientific research in this direction.

*Corresponding author: natzotova@yandex.ru 
At present, such categories as understanding (V.V. Znakov) [1], mental states (A.O. Prokhorov), personal and social self-determination (M.R. Ginzburg, A.B. Kupreychenko), life plans (K.A. Abulkhanova, E.I. Golovakha, A.A. Kronik, K.V. Karpinsky, N.A. Loginova and others) [2,3], self-conscious position (V.I. Panov) [4] have firmly entered the psychological problems of professional development. In modern science, the prevailing models can be considered the models of over-normative activity (V.I. Yasvin), a side product that transforms the product's activity (Ya.A. Ponomarev) [5], intellectual initiative (D.B. Bogoyavlenskaya) [6], goal-setting (O.K. Tikhomirov), personal choice (D.A. Leontiev) and many others. In general, as emphasized by many researchers of the processes of regulation by the subject of his life, the problem of phenomenology, forms, mechanisms of semantic regulation processes and the organization of his life by a person is poorly developed. The theoretical schemes of regulation prevailing in science cannot reveal the patterns of processes focused on fuzzy target states and criteria that are redefined and changed in the course of life. This is especially true for the problems of creative longevity in the teaching profession, value-semantic regulation of the teacher's life as a subject of his life path at the final stages of professionalization.

Teacher's professional longevity is an integral concept that includes various loci of his perception of his professional and life path. The processes of teacher's professional development include scientific knowledge gained in the learning process and his life experience, life values, cultural values and activities to which he devotes his life time and which largely determines his lifestyle. In addition, the teacher's personal meanings, individualizing his worldview, contribute to the construction of those models of professional reality, which reflecting his picture of the world, allow him to anticipate his future professional longevity according to certain scenarios. We are talking about models of professional behavior of teachers of mature age, which is set not only by objective or social situations, but also by the tendency to accept the value foundations of activity in the context of their age consciousness.

Research in the field of value-semantic regulation of activity shows the connection between meaning and the significance for the subject of certain objects, events, actions, which determine the adequacy and expediency of his life and professional plans. It has been established that the process of meaning formation is not isolated from activity, that meanings are generated and changed in activity $[7,8,9]$.

\section{Purpose and objectives of the research}

The general goal of our research is to highlight the value-semantic factors that determine the orientation of the teacher to the productive extension of his professional path beyond the retirement age. This goal has something in common not only with psychological research of the "third age", but also has significance in an interdisciplinary context, since it involves the analysis of professional activity as a subject of research not only in terms of its structure and content, but also as a basis for the formation of personal values system.

The main objectives of the research are the following:

1) to highlight value-semantic factors (target guidelines) that determine the teacher's focus on the productive extension of his professional path beyond the retirement age;

2) to select indicators of the type of value-semantic regulation of professional activity at its final stage;

3) to substantiate the need to develop a model of psychological and pedagogical support for the professional activities of teachers of pre- and retirement age. 


\section{Results}

The research program included blank testing, individual interviews, biographical information analysis, and the study of organizational culture. More than 700 Volgograd and the Volgograd region teachers were respondents.

This article highlights the main research results obtained using the in-depth interview method. The respondents were teachers of the Volgograd region $(n=40)$. All respondents have at least one higher pedagogical education, the average age of the sample is 61 years, the experience of professional activity is from 30 to 46 years (average -36 years). Career teachers made up about $30 \%$ of the sample. The female part of the sample made up over $90 \%$, which corresponds to the prevailing proportions in Russian education at the present time. The group of surveyed teachers included directors of educational institutions, teachers included in the list of " 100 best Russian teachers" working in schools from the list of "500 best schools in Russia", whose achievements were noted by municipal authorities and public organizations. In other words, we are talking about teachers who have achieved a high level of professionalism.

The in-depth interview technique included about 45 task-questions, which included general questions (career stages, main achievements, etc.); rating scales (respondents were asked to rate their professional path according to the scales "long - short", "successful (productive) path - the path of mistakes and failures (unproductive, useless)", etc. and comment on their choice). A separate group of questions related to the final stage of professional life. Taking into account the results of our previous research, the questionnaire also included questions built on the basis of the metaphor method, for example: "What do you associate with this event:"Leaving for a well-deserved rest?".

In general, we tried to draw up an interview program taking into account the three tasks indicated above, including the task of psychological support.The obtained data were processed using the methods of frequency analysis, content analysis, and classification. The respondents' answers were recorded without additional verification.

Research results.

1. Despite the duration of the interview (from 1.5 to 4 hours), the respondents expressed satisfaction with their participation in the research, in particular with the content of the interview in general. None of the respondents complained that he had to recall unpleasant episodes from his professional life. Many respondents expressed gratitude for their interest in their professional path. Thus, the task of psychological support for teachers of the "third age" can be realized in the course of the developed interview.

2. The inclusion of the metaphor technique in the interview program showed high information content in terms of meaningful expression by teachers of their experiences.

3. Some general trends can be identified:

A) Almost all respondents stated that they did not specifically plan their careers. The initial event that determined the interest in the profession, the majority of the respondents named a meeting with specific teachers: a primary school teacher, a subject teacher, a trainee teacher, etc. In addition, in the individual history of almost every respondent, an event was found that had a critical impact on the further course of his professional life. Thus, the practice of "career planning" in real life is not in demand for Russian teachers. The transition to another educational organization is perceived as a critical situation, even though new prospects are opening up. A possible transition to a "new life" - postprofessional - is also perceived as an undesirable event. It is interesting that for pensioners the possibility of returning to professional life appears in a negative sense, and the event "Leaving for a well-deserved rest" is associated with a holiday, liberation.

B) The obtained data make it possible to determine the main types of strategies for the transition to post-professional life in the surveyed teachers. 
1) A strategy to defer the transition. The teacher perceives the end of his professional life as a disaster, does not plan to retire in the short and medium term. The teacher considers himself productive, successful, ready to continue his activity, does not see himself as a pensioner and is ready to literally die at work. This strategy is also accompanied by the intensification of professional growth: the search for oneself in new forms of activity, active self-education, the implementation of new projects.

2) A smooth transition strategy. The teacher reflects the ongoing age-related changes, evaluating them as signs that limit the level of his effectiveness. In this regard, he tries to prepare for the transition - to complete business, think over retirement activities, switches to a measured rhythm of life, pays more attention to his family and his health. There are plans to retire in the near or medium term. As a rule, the teacher calls the end of the career from two to five years.

3) Strategy of the forced finish. The teacher who has chosen this strategy understands that his professional path is coming to an end, reacts to emerging age-related difficulties (problems with his health, health of parents and children), but does not want to retire yet. The teacher is in a kind of dead end, since productive work at the same high level becomes more and more problematic due to external or internal factors. However, the teacher does not agree to choose "living out" in the profession, understanding the responsibility for the quality of his work. In this case, a decision is often made "suddenly" to terminate a professional career.

Table 1. Indicators of the type of value-semantic regulation of the teacher's professional activity at the final stage of his career.

\begin{tabular}{|l|l|l|l|}
\hline $\begin{array}{l}\text { Career } \\
\text { completion type }\end{array}$ & $\begin{array}{l}\text { Attitude to your } \\
\text { health }\end{array}$ & $\begin{array}{l}\text { Reflection of a } \\
\text { professional level }\end{array}$ & $\begin{array}{l}\text { Combining life and } \\
\text { professional goals }\end{array}$ \\
\hline Postponement & $\begin{array}{l}\text { Caring for health } \\
\text { promotion, recovery } \\
\text { during periods of rest, } \\
\text { the presence of } \\
\text { "healthy" hobbies }\end{array}$ & $\begin{array}{l}\text { Constant concern for } \\
\text { professional growth, } \\
\text { striving to expand } \\
\text { professional } \\
\text { opportunities }\end{array}$ & $\begin{array}{l}\text { Mandatory } \\
\text { coincidence of life } \\
\text { and professional } \\
\text { goals }\end{array}$ \\
\hline $\begin{array}{l}\text { Smooth } \\
\text { transition }\end{array}$ & $\begin{array}{l}\text { Saving energy, } \\
\text { striving "not to } \\
\text { overexert yourself" }\end{array}$ & $\begin{array}{l}\text { Monitoring success, } \\
\text { analyzing the causes } \\
\text { of difficulties for the } \\
\text { possibility of } \\
\text { mistakes } \\
\text { compensation and } \\
\text { correction }\end{array}$ & $\begin{array}{l}\text { Separation of life } \\
\text { and professional } \\
\text { goals }\end{array}$ \\
\hline Forced finish & $\begin{array}{l}\text { Working too hard, } \\
\text { overstrain, conflict }\end{array}$ & $\begin{array}{l}\text { Compliance analysis } \\
\text { of activities with } \\
\text { formal requirements }\end{array}$ & $\begin{array}{l}\text { Non-obligatory } \\
\text { combination of } \\
\text { professional and life } \\
\text { goals }\end{array}$ \\
\hline
\end{tabular}

C) The main system of target guidelines for the professional self-determination of the surveyed teachers is based on the values of Soviet society: duty and responsibility to society for the education and upbringing of the younger generation ("Who else but me?", "Give my heart to children"), love for children and for pedagogy as a kind of activity, altruism. At the same time, the respondents often note that the target guidelines of younger teachers are completely different, and the facts of the early departure from the profession of such teachers show their incompatibility with the values of the teaching profession.

D) Among the indicators of the type of value-semantic regulation of professional activity at its final stage, an essential role is played by:

- the teacher's attitude to his health as the central resource of his professional activity; 
- reflection by the teacher of his current level of professional efficiency;

-the teacher's combination of his life and professional goals.

At the same time, content analysis allows one to correlate the type of career completion strategy with the selected indicators (Table 1).

\section{Conclusion}

So, a long-term professional career of a teacher is based on a meaningful professional orientation in combination with adaptation to the requirements of an educational organization and a desire to maintain an optimal state of health. In a psychological sense, this is expressed in a high level of general social activity, self-confidence, resilience, as shown in our previous studies [10].

The content of the model of psychological and pedagogical support for teachers of retirement age, in our opinion, may be associated with the search for such forms of interaction in which these persons should be assigned the role of mentors, translators of their experience, who primarily provide moral support to younger colleagues. In addition, it is necessary to implement a model that would provide for the development of mature teachers' readiness for professional activity in situations of uncertainty, which is extremely important for the current situation in education, in understanding the time perspective of their professional and personal development, in readiness for innovative transformations and renewal strategies. activities, in enhancing professional reflection.

The reported study was funded by RFBR according to the research project № 18-013-00712.

\section{References}

1. V.V. Znakov, The theoretical foundations of the psychology of understanding the multidimensional world of man, Questions of Psychology, 4, 16-29 (2014)

2. N.A. Loginova, Human life way as a problem of psychology, Questions of Psychology, 1, 103-109 (1985)

3. K.A. Abulkhanova, Methodological principle of a subject: study of person's life course, Psychological journal, 2, 5-18 (2014)

4. V.I. Panov, Stages of mastering professional actions: an ecopsychological model of becoming subjectivity, Moscow University Psychology Bulletin, 4, 16-25 (2016)

5. Ya.A. Ponomarev, Research of human creative potential, Psychological journal, 1, 3$11(1991)$

6. D.B. Bogoyavlenskaya, O.A. Klyueva, Discovering the nature of competitive personality, Psychology in Russia: state of the art, 5, 67-80 (2012)

7. A.G. Asmolov, B.S. Bratus, B.V. Zeygarnik, On some research perspectives of semantic formations of personality, Questions of Psychology, 3, 35-41 (1979)

8. F.E. Vasilyuk, Psychology of emotions (MSU, Moscow, 1984)

9. D.A. Leontiev, The psychology of meaning: nature, structure and dynamics of meaningful reality (The meaning, Moscow, 2003)

10. N.G. Zotova, S.A. Peredelskaya, M.Yu. Tikhomirov, Professional Longevity as a Problem of the Value-Semantic Regulation of Teacher Activity, Behavioral Sciences, 9 (12) (2019) 